\title{
Comparison of electrospray ionization, atmospheric pressure chemical ionization and atmospheric pressure photoionization for determining estrogenic chemicals in water by liquid chromatography tandem mass spectrometry with chemical derivatizations
}

\author{
Guang-Wen Lien, Chia-Yang Chen*, Gen-Shuh Wang \\ Institute of Environmental Health, College of Public Health, National Taiwan University, Taipei 10055, Taiwan
}

\section{A R T I C L E I N F O}

\section{Article history:}

Received 23 September 2008

Received in revised form 5 December 2008

Accepted 11 December 2008

Available online 24 December 2008

\section{Keywords:}

Dansyl chloride

Matrix effect

Pentafluorobenzyl bromide

UPLC

Steroid estrogen

2D-LC

\begin{abstract}
A B S T R A C T
This study compared the sensitivities and matrix effects of four ionization modes and four reversedphase liquid chromatographic (LC) systems on analyzing estrone (E1), 17 $\beta$-estradiol (E2), estriol (E3), 17 $\alpha$-ethinylestradiol (EE2), 4-nonylphenol (NP), 4-tert-octylphenol (OP), bisphenol A (BPA) and their derivatives of dansyl chloride or pentafluorobenzyl bromide (PFBBr) in water matrixes using a triple-quadrupole mass spectrometer with selected reaction monitoring (SRM). The four probes were electrospray ionization (ESI), atmospheric pressure chemical ionization (APCI), atmospheric pressure photoionization (APPI) and APCI/APPI; the four LC systems were ultra-performance liquid chromatography (UPLC) with or without post-column split, a mixed-mode column and two-dimensional LC (2D-LC). Dansylated compounds with ESI at UPLC condition had the most intense signals and less matrix effects of the various combinations of ionization and LC systems. The on-column limits of detection (LODs) of dansylated estrogens by SRM were $0.05-0.20 \mathrm{pg}$, and the LODs in sewage treatment plant effluent and in river water were $0.23-0.52$ and $0.56-0.91 \mathrm{ng} / \mathrm{L}$, respectively. The LODs using selected ion monitoring (SIM) reached low ng/L levels in real samples and measured concentrations were comparable with those of SRM.
\end{abstract}

(c) 2008 Elsevier B.V. All rights reserved.

\section{Introduction}

Feminizing contaminants of steroid estrogens, detergent degradates and plasticizers have caused a worldwide concern. They may influence the ecosystem at trace levels and affect human health through their contamination of drinking water. Natural estrogens $17 \beta$-estradiol (E2) and its synthetic analogue $17 \alpha$-ethinylestradiol (EE2), an ingredient in oral contraceptives, are the most estrogenic. Moreover, their major metabolites, estrone (E1) and estriol (E3), are still bioactive. These steroid estrogens enter the water environment via the urine of humans and animals in the form of hydrophilic glucuronide and sulfate conjugates [1], which are biologically inactivated [2]. However, they are likely to be deconjugated in sewage treatment systems and converted to estrogenically active free forms [3]. 4-nonylphenol (NP), 4-tert-octylphenol (OP) and bisphenol A (BPA), which are all xenoestrogens, can affect normal endocrine functions. Although they are less potent, they are usually found in much higher concentrations in water $(\mathrm{ng} / \mathrm{L}-\mu \mathrm{g} / \mathrm{L})$ [3-6]. These

\footnotetext{
* Corresponding author. Tel.: +8862 3366 8101; fax: +886223519557.

E-mail address: dbms@ntu.edu.tw (C.-Y. Chen).
}

xenoestrogens are released into the water environment from daily usage of non-ionic surfactants and plasticizers.

Atmospheric pressure photoionization (APPI) is an emerging source, which is capable of ionizing nonpolar compounds and is possibly less susceptible to matrix effects. In addition, dualsource ionization (e.g. atmospheric pressure chemical ionization (APCI)/APPI combo in this study) expands the range of compounds that can be simultaneously analyzed. Although most studies determined feminizing chemicals with electrospray ionization (ESI) coupled with LC/MS(/MS) [7-9], the suitability of APCI and APPI deserve further exploration.

Matrix effect, which co-eluting components from the matrix or the mobile phase may enhance or suppress signals, is an important issue in using LC/MS/MS. Selective extraction, additional clean-up, efficient LC separation or change of mobile phase compositions may reduce matrix effects [10]. Furthermore, while the use of suitable internal standards (e.g. isotope-labeled chemicals) may correct signal irreproducibility, this approach will not be able to overcome the loss in sensitivity caused by matrix effects. Some studies utilized direct online extraction or post-column split to minimize matrix effects and simplify the sample preparation. A novel column developed on September 2006 combines both size exclusion and 
reverse-phase chemistry to separate small molecules from complex matrix [11]; to the best of our knowledge, one study has analyzed drugs in bovine serum using the mixed-mode column [11]. A restricted access material (RAM) pre-column, with a similar separation mechanism to the mixed-mode column, has also been applied on analyzing food, biological and environmental samples $[12,13]$. However, the RAM pre-column is an alkyl-diol silica (ADS) column and provides little chromatographic separation for small molecules; it requires a column switch to connect it with an additional analytical column for chromatographic separation (a two-dimensional LC, 2D-LC). In addition, a post-column split delivers only a portion of LC flow into the MS, which may substantially decrease matrix effects, especially when a flow rate into ESI interface was decreased to nanoflow of $0.1 \mu \mathrm{L} / \mathrm{min}[14,15]$. This nanosplit requires special nanospray probes, which is not amenable to a conventional ESI interface, whose flow rates can be only as low as $20-50 \mu \mathrm{L} / \mathrm{min}$. Reports on the mixed-mode column, 2D-LC and post-column split are very limited in environmental analysis and so little is known about their ability to reduce matrix effects.

Recently, there has been an increase in the number of studies using ultra-performance liquid chromatography (UPLC) combined with MS/MS. UPLC takes advantage of smaller packing particles $(<2.0 \mu \mathrm{m})$ that enable high flow rates for fast chromatography without sacrificing separation efficiency, and signal-to-noise $(\mathrm{S} / \mathrm{N})$ ratios of analytes are increased because of sharp peaks. However, to best of our knowledge none have used UPLC/MS/MS to study estrogenic compounds in water.

Steroid estrogens and phenolic xenoestrogens are weak acids and their ionization on ESI and APCI are not very efficient compared with other more polar chemicals. Chemical derivatization can add on moieties improving ionization and enhance signals. For example, dansyl chloride or pentafluorobenzyl bromide (PFBBr) can react with phenolic groups, significantly improving sensitivity [16-18]. By adding the dansyl moiety with ESI interface, signal intensity may be increased as much as three orders of magnitude $[16,19,20]$. This technique has been also found to improve the sensitivity in APCI interface when used to measure steroid estrogens [21]. To date no dansyl derivatives have been analyzed with APPI interface. PFBBr derivatives can capture soft electrons in APCI, resulting in unstable metastic ions, and cause subsequent dissociation to generate negative ions through the loss of pentafluorobenzyl radical (electron-capture atmospheric pressure negative ionization, EC-APNI). For estrone, the use of PFBBr derivatives in ECAPNI can enhance efficiency of ionization as much as 25 times that of APCI alone [18]. This method has been also used in APPI with a high toluene dopant flow rate (e.g. $200 \mu \mathrm{L} / \mathrm{min}$ or higher) and was found to be able to detect as little as $0.17 \mathrm{pg}$ of 2,4-dinitrophenol [22], whereas for PFBBr-derivatized estrone, signal enhancement (1.4-9.8 times) was less than that using EC-APNI [18]. Our group previously reported that dansylated estrogens with ESI interface provided better signal intensities than that PFBBr derivatives with EC-APNI, but obvious signal suppression was encountered with ESI when analyzing complex matrixes such as river water and effluents from sewage treatment plants [23].

In this study, we investigated signal intensity and matrix effects on various chromatographic systems (UPLC with or without flow split, mixed-mode column, 2D-LC) and several ionization modes (ESI+, ESI-, APCI+, APCI-, APPI+, APPI-, APCI/APPI+, APCI/APPI-) for both estrogenic compounds and their derivatives of dansyl chlorine and PFBBr. In addition, the study is unique in that it first optimized the operation conditions specific for each ionization methods, including those for LC columns, mobile phase flow rates and compositions. Previous studies usually compared the performance of different ionization sources under only one analytical column kept at a constant solvent flow rate, isocratic chromatography, the same injection volume, or flow injection analysis alone
[24,25]. However, the conclusions based on the results using nonoptimized parameters of various ionization methods could be controversial. The main purpose of the study was to find out the best combination of a chromatographic system and an ionization method with satisfactory sensitivity using low volumes of water samples or single quadrupole MS. The final method was validated using river water and effluents from a sewage treatment plant (STP).

\section{Experimental}

\subsection{Chemicals and reagents}

Estrone, 17 $\beta$-estradiol, estriol, $17 \alpha$-ethinylestradiol, 4-tertoctylphenol, bisphenol $A$, and bisphenol A- $\mathrm{d}_{16}$ (as a recovery standard) were obtained from Sigma/Aldrich (Saint Louis, MO, USA; purity $>98 \%$ ). The technical mixture of nonylphenol was supplied by Riedel-de Haën (Seelze, Germany; purity $>94 \%$ ). $2,4,16,16-{ }^{2} \mathrm{D}_{4}$-estrone, $2,4,16,16-{ }^{2} \mathrm{D}_{4}-17 \beta$-estradiol, $2,4,17-{ }^{2} \mathrm{D}_{3}$ $16 \alpha$-hydroxy-17 $\beta$-estradiol, $\quad 2,4,16,16-{ }^{2} \mathrm{D}_{4}-17 \alpha$-ethinylestradiol and 4-n-Octyl-d17-phenol were bought from $C / D / N$ Isotopes (Pointe-Claire, Quebec, Canada; purity >98\%). Bisphenol A- ${ }^{13} \mathrm{C}_{12}$ was purchased from Cambridge Isotope Laboratories (Andover, MA, USA; purity $>99 \%$ ). Dansyl chloride (5-(dimethylamino) naphthalene-1-sulfonyl chloride, $\sim 95 \%$ purity), pentafluorobenzyl bromide (PFBBr, purity $>99 \%$ ), 4-methylmorpholine (purity $>99.5 \%$ ), sodium hydrogen carbonate, and potassium hydroxide were purchased from Sigma/Aldrich. Milli-Q water was obtained from a Millipore water purification system (Milford, MA, USA). Formic acid (purity $>88 \%$ ) and formaldehyde (purity $>37 \%$ ) were provided by J.T. Baker (Phillipsburg, NJ, USA). Solvents, including methanol, acetone, $n$-heptane, acetonitrile and toluene, were all HPLC grade from J.T. Baker.

\subsection{Extraction}

The procedure used to extract estrogenic compounds from the water sample has been previously described [9]. Briefly, water samples were spiked with internal standards and then filtered through 90-mm PVDF membranes (pore size $0.45 \mu \mathrm{m}$ ) to remove suspended solids before extraction. Extraction was performed using 50-mm Bakerbond PolarPlus C18 Speedisks (J.T. Baker), followed by a cleanup using $40 \%$ methanol/60\% Milli-Q water (v/v). The disks were dried for $10 \mathrm{~min}$ under a vacuum of about $-25 \mathrm{kPa}$. Analytes were eluted with three portions of $5-\mathrm{mL} 50 \%$ methanol/50\% dichloromethane $(\mathrm{v} / \mathrm{v})$. The eluates were filtered through $25-\mathrm{mm}$ PTFE syringe filters (pore size $0.2 \mu \mathrm{m}$ ) and concentrated to dryness at $45^{\circ} \mathrm{C}$ by a SpeedVac concentrator (Thermo Savant SPD 1010, Holbrook, NY, USA). The residues were re-dissolved by spiking recovery standard and then reacted with dansyl chloride reagents.

\subsection{Derivatization}

\subsubsection{Dansyl chloride derivatization}

The procedure used to derive dansyl chloride was based on EE2 derivatization method used by Penzes and Oertel [26] and Shou et al. [19]. Briefly, $0.9 \mathrm{~mL}$ of $100 \mu \mathrm{g} / \mathrm{mL}$ analytes in acetone was vortexed for $1.0 \mathrm{~min}$ with $0.1 \mathrm{~mL}$ of $1 \mathrm{mg} / \mathrm{mL}$ dansyl chloride in dry acetone followed by mixing with $0.01 \mathrm{~mL}$ of $0.1 \mathrm{~N}$ sodium hydroxide for $1.0 \mathrm{~min}$. The mixture was kept at $50^{\circ} \mathrm{C}$ for $30 \mathrm{~min} .5 \mathrm{~mL}$ of $n$-heptane was added to the mixture which was then shaken for $3 \mathrm{~min}$. It was centrifuged at $3000 \mathrm{rpm}$ for $10 \mathrm{~min}$ and refrigerated at $-20^{\circ} \mathrm{C}$. Once it had separated into two layers, the organic layer was collected and filtered through $0.20-\mu \mathrm{m}$ PTFE into another glass tube. The aqueous layer was discarded. The organic layer was evaporated to dryness at $45^{\circ} \mathrm{C}$ by a SpeedVac concentrator. The residue was re-dissolved 


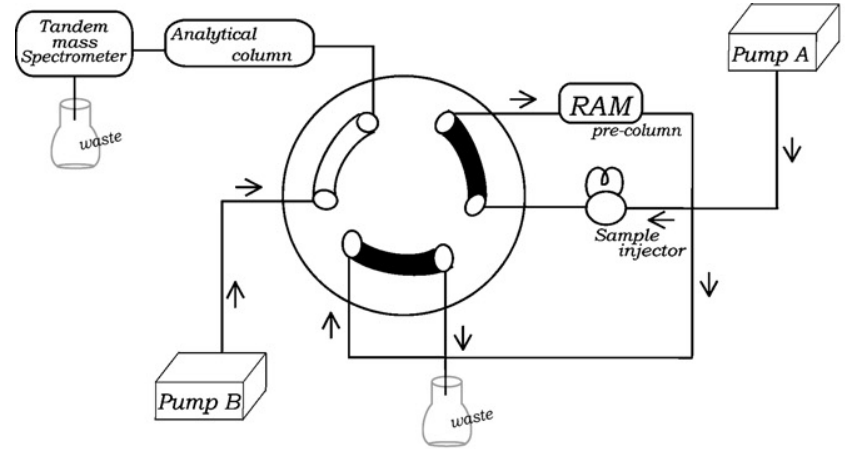

(a)

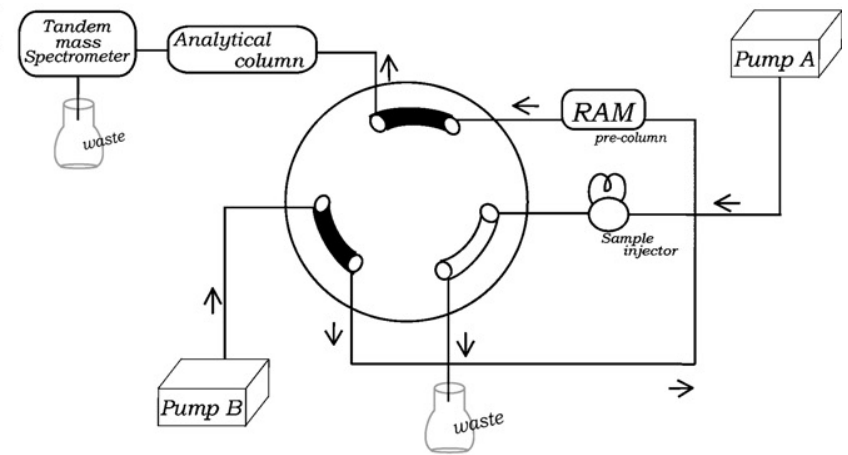

(b)

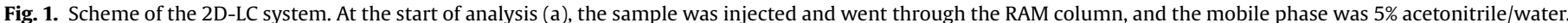

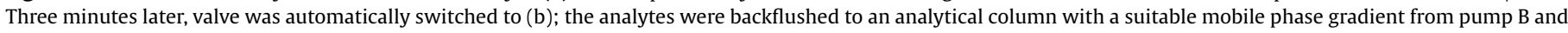
then introduced to the tandem mass spectrometer.

with $0.9 \mathrm{~mL}$ of methanol to optimize the parameters of operations on the MS. However, the above protocol cannot be directly applied to the derivatization of water samples and needs another protocol that was modified from Anari et al. [16] and Nelson et al. [21]. $100 \mu \mathrm{L}$ of $0.9 \mathrm{ng} / \mu \mathrm{L}$ (for ESI analysis) and $250 \mu \mathrm{L}$ of $0.36 \mathrm{ng} / \mu \mathrm{L}$ (for APPI, $\mathrm{APCI}$ and $\mathrm{APCI} / \mathrm{APPI}$ analysis), both in acetone, were vortexed with 250 - and $625-\mu \mathrm{L}$ sodium bicarbonate buffer $(10 \mathrm{mM}$, pH adjusted with $\mathrm{NaOH}_{(\mathrm{aq})}$ to 10.5), respectively. To these standards were added 250 and $625 \mu \mathrm{L}$ of $1-\mathrm{mg} / \mathrm{mL}$ solution of dansyl chloride, respectively. They were then incubated at $60^{\circ} \mathrm{C}$ for $3.0 \mathrm{~min}$ and evaporated to dryness in a SpeedVac concentrator. The residues were reconstituted with 100 and $250 \mu \mathrm{L}$ of methanol, respectively. Then, $4 \mu \mathrm{L}$ (for ESI mode) and $10 \mu \mathrm{L}$ (for APPI, APCI and APCI/APPI mode) were injected into LC/MS/MS for comparative analysis.

\subsection{2. $\mathrm{PFBBr}$ derivatization}

$\mathrm{PFBBr}$ was derived based on a procedure reported by Singh et al. [18]. We vortexed $250-\mu \mathrm{L}$ mixture standards of native $(0.36 \mathrm{ng} / \mu \mathrm{L})$ analytes in methanol with $250 \mu \mathrm{L}$ of potassium hydroxide in anhydrous ethanol (8:1000; w/v). We then added $250 \mu \mathrm{L}$ of $5 \% \mathrm{PFBBr}$ in acetonitrile. The mixture was baked at $60^{\circ} \mathrm{C}$ for $30 \mathrm{~min}$ and then evaporated to dryness in a SpeedVac concentrator. The residue was reconstituted with $250 \mu \mathrm{L}$ of methanol, and $10 \mu \mathrm{L}$ was injected into $\mathrm{LC} / \mathrm{MS} / \mathrm{MS}$ for comparative analysis.

\subsection{LC systems and analytical columns}

\subsubsection{The UPLC with or without post-column split}

A Waters BEH $C_{18}$ column $(2.1 \mathrm{~mm} \times 100 \mathrm{~mm}, 1.7 \mu \mathrm{m})$ was used for ESI and APPI at a flow rate of $0.5 \mathrm{~mL} / \mathrm{min}$, while native analytes in APPI were set at $0.2 \mathrm{~mL} / \mathrm{min}$ for better signal intensities. A Sepax GP-C 18 column $(3.0 \mathrm{~mm} \times 100 \mathrm{~mm}, 1.7 \mu \mathrm{m})$ was used for APCI and APCI/APPI at a flow rate of $1.0 \mathrm{~mL} / \mathrm{min}$. Post-column split (split ratio $=1: 5$ ) was tested on ESI.

\subsubsection{The mixed-mode column}

A Shodex ODP $2 \mathrm{HP}-2 \mathrm{D}(2.0 \mathrm{~mm} \times 150 \mathrm{~mm}, 5 \mu \mathrm{m})$ was used for ESI and APPI at a flow rate of $0.2 \mathrm{~mL} / \mathrm{min}$, while dansylated analytes in APPI were set at $0.5 \mathrm{~mL} / \mathrm{min}$. A Shodex ODP $2 \mathrm{HP}-4 \mathrm{D}$ column $(4.6 \mathrm{~mm} \times 150 \mathrm{~mm}, 5 \mu \mathrm{m})$ was used for APCI and APCI/APPI at a flow rate of $1.0 \mathrm{~mL} / \mathrm{min}$.

\subsubsection{D-LC system with RAM pre-column}

This system was composed of a VICI six-port switching valve (Valco Instruments Inc., Houston, TX, USA) and an extra isocratic pump (Jasco PU-980, Tokyo, Japan) (Fig. 1). The elution profiles of the RAM pre-column (LiChrosphere RP-4ADS $(25 \mathrm{~mm} \times 2 \mathrm{~mm}$, $25 \mu \mathrm{m})$ ) for effluent of sewage treatment plants and river water were monitored with a UV detector set at $280 \mathrm{~nm}$. The injection volume was $50 \mu \mathrm{L}$ of each extract, and the flow rate of mobile phase of Milli-Q water-acetonitrile (95:5, v/v) through RAM pre-column was set at $1 \mathrm{~mL} / \mathrm{min}$. The time required to elute major matrix components was less than 3 min (profile not shown). Based on this result, the valve was switched after $3 \mathrm{~min}$ to backflush the analytes into an analytical column. A Thermo Hypersil Gold column $(2.1 \mathrm{~mm} \times 50 \mathrm{~mm}, 1.9 \mu \mathrm{m}$, Bellefone, PA, USA) was used for ESI and APPI, which flow rate was $0.2 \mathrm{~mL} / \mathrm{min}$, while dansylated analytes in APPI was set at $0.5 \mathrm{~mL} / \mathrm{min}$. A Thermo BetaBasic $\mathrm{C}_{18}$ column $(4.6 \mathrm{~mm} \times 150 \mathrm{~mm}, 3 \mu \mathrm{m})$ was used for APCI and APCI/APPI set at a flow rate of $1.0 \mathrm{~mL} / \mathrm{min}$. All chromatographic separations including UPLC, mixed-mode column and 2D-LC were performed at $60^{\circ} \mathrm{C}$ (Table 1).

\subsection{Instruments and parameters}

The separation and detection were performed on a Waters Acquity UPLC system (Waters Corporation, Milford, MA, USA) coupled with a Waters Quattro Premier XE triple quadrupole mass spectrometer. The UPLC/MS/MS system was controlled by

Table 1

Different LC systems and ionization modes for both native compounds and derivatives with PFBBr or dansyl chloride.

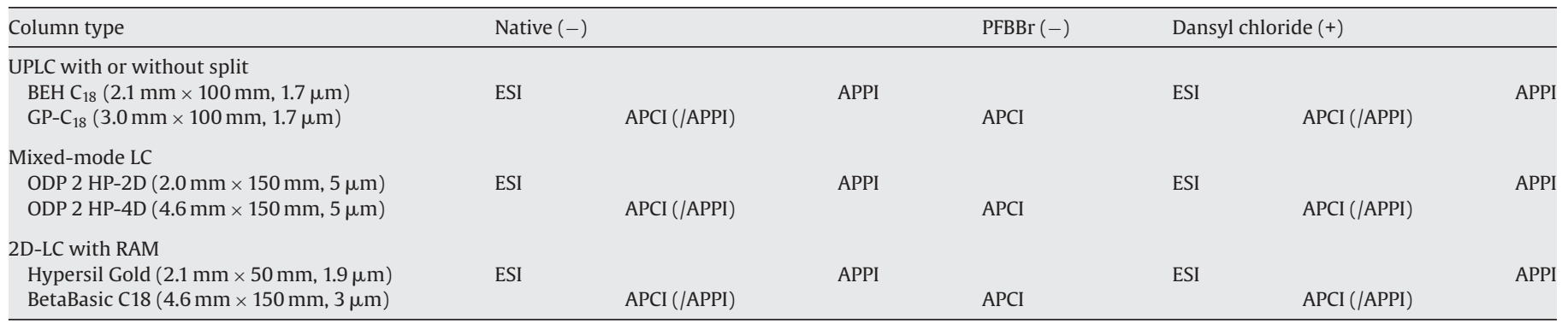


Table 2

Major MS parameters for different analytes and ionization methods.

\begin{tabular}{|c|c|c|c|c|c|c|c|c|c|}
\hline \multirow[t]{2}{*}{ Parameter } & \multicolumn{4}{|c|}{ Native } & \multirow{2}{*}{$\frac{\mathrm{PFBBr}}{\mathrm{APCI}-}$} & \multicolumn{4}{|c|}{ Dansyl chloride } \\
\hline & ESI- & $\mathrm{APCI}-$ & APPI- & APCI/APPI- & & ESI+ & $\mathrm{APCI}+$ & APPI+ & $\mathrm{APCI} / \mathrm{APPI}+$ \\
\hline Source temperature $\left({ }^{\circ} \mathrm{C}\right)$ & 120 & 150 & 150 & 150 & 150 & 120 & 120 & 120 & 120 \\
\hline Desolvation temperature $\left({ }^{\circ} \mathrm{C}\right)$ & 400 & 600 & 600 & 600 & 400 & 450 & 500 & 700 & 500 \\
\hline Cone gas flow $(\mathrm{L} / \mathrm{h})$ & 50 & 0 & 0 & 0 & 0 & 0 & 0 & 50 & 0 \\
\hline Desolvation gas flow $(\mathrm{L} / \mathrm{h})$ & 900 & 75 & 200 & 75 & 150 & 1000 & 600 & 200 & 600 \\
\hline Corona $(\mu \mathrm{A})$ & & 30 & & 30 & 30 & & 2.8 & & 2.8 \\
\hline Capillary (kV) & 3 & & & & & 2.8 & & & \\
\hline Repeller (kV) & & & 2 & 2 & & & & 3 & 3 \\
\hline
\end{tabular}

MassLynx V4.1 with QuanLynx Application Manager and the data were acquired and processed using MassLynx V4.1. Instrumental parameters in various ionization methods were optimized to achieve maximal analyte signal intensities.

Changes of the desolvation gas $\left(\mathrm{N}_{2}\right)$ flow rate and source temperature did not produce significantly different signals in either ESI or APPI interface when flow rates of mobile phase were at either 0.2 or $0.5 \mathrm{~mL} / \mathrm{min}$, so these two parameters were kept the same for these two flow rates. Major parameters are summarized in Table 2. Extractor voltage was $3.0 \mathrm{~V}$ and RF lens voltage was $0 \mathrm{~V}$. Collision gas was argon at $3 \times 10^{-3}$ mbar. Ion energy 1 and 2 were set at 0.3 and 3, respectively. Both LM 1 and LM 2 resolution were set at 15 . The multiplier voltage was set at $650 \mathrm{~V}$. Ions were monitored by selected reaction monitoring (SRM) as shown in Table 3. Dansylated analytes produced intense precursor ions with $\mathrm{m} / z[\mathrm{M}+233.8]^{+}$, and the collision-induced dissociation produced intense product ions with $\mathrm{m} / \mathrm{z} 171^{+}$and $\mathrm{m} / \mathrm{z} 156^{+}$, corresponding to the 5-(dimethylamino)-naphthalene moiety and the loss of one methyl group from the $m / z 171^{+}$, respectively $[19,23]$. PFBBr derivatives produced the same precursor ions as the underivatized ones with $m / z$ [M-H] $]^{-}[23]$. Several LC mobile phase compositions were tested to obtain good separation and peak shapes. Data points across the peak were no less than 20 to ensure the integration precision.

\subsubsection{Dansyl derivatives}

2.5.1.1. ESI (+). $10 \mathrm{mM}$ formic acid ( $\mathrm{pH}$ 2.9) (A) and acetonitrile (B) were used as the mobile phase. There were three LC column conditions. (1) A BEH $\mathrm{C}_{18}$ column with and without split had a gradient of $50 \%$ B for $0.2 \mathrm{~min}$, followed by a linear gradient to $85 \% \mathrm{~B}$ in $0.8 \mathrm{~min}$, and then to $100 \% \mathrm{~B}$ in $1.5 \mathrm{~min}$, at which point it was held at $100 \%$ $\mathrm{B}$ for $0.7 \mathrm{~min}$ before being returned to initial condition. The column was re-equilibrated for $1.0 \mathrm{~min}$. (2) An ODP $2 \mathrm{HP}-2 \mathrm{D}$ column had a gradient of $50 \%$ B for $2.0 \mathrm{~min}$, followed by a linear gradient to $85 \% \mathrm{~B}$ in $1.0 \mathrm{~min}$, and then to $90 \% \mathrm{~B}$ in $2.0 \mathrm{~min}$, at which point it was held at $90 \% \mathrm{~B}$ for $1.5 \mathrm{~min}$ before being returned to initial condition. The column was re-equilibrated for $4.5 \mathrm{~min}$. (3) A RAM coupled with a Thermo Hypersil Gold column had a gradient of $30 \%$ B for $3.0 \mathrm{~min}$, followed by a linear gradient to $50 \% \mathrm{~B}$ in $1.0 \mathrm{~min}$, then to $85 \% \mathrm{~B}$ in $2.0 \mathrm{~min}$, and then to $100 \% \mathrm{~B}$ in $4.0 \mathrm{~min}$, at which point it was held at $100 \%$ B for $2.0 \mathrm{~min}$ before being returned to initial condition. The column was re-equilibrated for $2.0 \mathrm{~min}$.

2.5.1.2. APPI (+). $10 \mathrm{mM}$ formic acid (A) and acetonitrile (B) were used as the mobile phase. There were three LC conditions. (1) A BEH $\mathrm{C}_{18}$ column had a gradient was set the same as ESI mode. (2) An ODP 2 HP-2D column had a gradient of $50 \%$ B for $1.0 \mathrm{~min}$, followed by a linear gradient to $70 \% \mathrm{~B}$ in $1.0 \mathrm{~min}$, and then to $85 \% \mathrm{~B}$ in $2.0 \mathrm{~min}$, at which point it was held at $85 \%$ B for 1.0 min before being returned to initial condition. The column was re-equilibrated for $2.0 \mathrm{~min}$. (3) A RAM coupled with a Thermo Hypersil Gold column had a gradient of $30 \% \mathrm{~B}$ for $3.0 \mathrm{~min}$, followed by a linear gradient to $50 \% \mathrm{~B}$ in $1.0 \mathrm{~min}$, then to $85 \% \mathrm{~B}$ in $4.0 \mathrm{~min}$, and then to $100 \% \mathrm{~B}$ in $4.0 \mathrm{~min}$. It was held at $100 \% \mathrm{~B}$ for $1.0 \mathrm{~min}$ before being returned to initial condition. The column was re-equilibrated for $2.0 \mathrm{~min}$.

2.5.1.3. APCI (+) and APCI/APPI (+). $10 \mathrm{mM}$ formic acid (A) and methanol (B) were used as the mobile phase. There were three LC conditions. (1) A GP- $\mathrm{C}_{18}$ column had an initial gradient of $50 \% \mathrm{~B}$, followed by a linear gradient to $85 \%$ B for $0.5 \mathrm{~min}$, and then to $100 \%$ $\mathrm{B}$ in $1.7 \mathrm{~min}$, at which point it was held at $100 \% \mathrm{~B}$ for $0.3 \mathrm{~min}$ before being returned to initial condition. The column was re-equilibrated for 2 min. (2) An ODP 2 HP-4D column had an initial gradient of $50 \% \mathrm{~B}$, followed by a linear gradient to $85 \% \mathrm{~B}$ for $3.0 \mathrm{~min}$, and then to $100 \% \mathrm{~B}$ in $3.0 \mathrm{~min}$. It was held at $100 \% \mathrm{~B}$ for $2.0 \mathrm{~min}$ before being returned to initial condition. The column was re-equilibrated for 2.0 min. (3) A RAM coupled with a BetaBasic $\mathrm{C}_{18}$ column had a gradient of $30 \% \mathrm{~B}$ for $3 \mathrm{~min}$, followed by a linear gradient to $50 \% \mathrm{~B}$ in $1.0 \mathrm{~min}$, then to $85 \% \mathrm{~B}$ in $2.0 \mathrm{~min}$, and then to $100 \% \mathrm{~B}$ in $2.0 \mathrm{~min}$, at which point it was held at $100 \%$ B for $2.0 \mathrm{~min}$ before being returned to initial condition. The column was re-equilibrated for $2.0 \mathrm{~min}$.

\subsection{2. $\mathrm{PFBBr}$ derivatives}

2.5.2.1. APCI (-). Water $(A)$ and methanol $(B)$ were used as the mobile phase. There were three LC conditions. (1) A GP- $C_{18}$ column had a gradient of $70 \% \mathrm{~B}$ for $0.2 \mathrm{~min}$, followed by a linear gradient to $90 \%$ B in $0.8 \mathrm{~min}$, and then to $100 \%$ B in $2.2 \mathrm{~min}$. It was held at $100 \%$ $\mathrm{B}$ for 0.2 min before being returned to initial condition. The column was re-equilibrated for $1.0 \mathrm{~min}$. (2) An ODP2 HP-4D column had a gradient of $70 \%$ B for $2 \mathrm{~min}$, followed by a linear gradient to $95 \% \mathrm{~B}$ in $3.0 \mathrm{~min}$. It was held at $95 \% \mathrm{~B}$ for $2.0 \mathrm{~min}$ before being returned to initial condition. The column was re-equilibrated for $2.0 \mathrm{~min}$. (3) A RAM coupled with a BetaBasic $\mathrm{C}_{18}$ column had a gradient of $30 \% \mathrm{~B}$ for $3.0 \mathrm{~min}$, followed by a linear gradient to $75 \% \mathrm{~B}$ in $1.0 \mathrm{~min}$, and then to $100 \%$ B in $4.0 \mathrm{~min}$, at which point it was held at $100 \% \mathrm{~B}$ for $4.0 \mathrm{~min}$ before being returned to initial condition. The column was re-equilibrated for $3.0 \mathrm{~min}$.

\subsubsection{Native analytes}

2.5.3.1. ESI (-). $10 \mathrm{mM} 4$-methylmorphline ( $\mathrm{pH} 9.5$ ) (A) and acetonitrile (B) were used as mobile phase. There were three LC conditions. (1) A BEH $\mathrm{C}_{18}$ column with and without split had a gradient of $10 \%$ B for $0.2 \mathrm{~min}$, followed by a linear gradient to $40 \% \mathrm{~B}$ in $0.8 \mathrm{~min}$, then to $70 \% \mathrm{~B}$ in $1.7 \mathrm{~min}$, and then to $95 \% \mathrm{~B}$ in $0.5 \mathrm{~min}$. It was kept at $95 \%$ B for 0.6 min before being returned to the initial condition. The column was re-equilibrated for $1.7 \mathrm{~min}$. (2) An ODP 2 HP-2D column had a gradient of $10 \%$ B for $2.0 \mathrm{~min}$, followed by a linear gradient to $50 \% \mathrm{~B}$ in $3.0 \mathrm{~min}$, and then to $70 \% \mathrm{~B}$ in $8.0 \mathrm{~min}$, at which point it was held at $70 \% \mathrm{~B}$ for $2.0 \mathrm{~min}$ before being returned to initial condition. The column was re-equilibrated for $4.0 \mathrm{~min}$. (3) A RAM coupled with a Thermo Hypersil Gold column had a gradient of $30 \%$ B for $3.0 \mathrm{~min}$, followed by a linear gradient to $50 \% \mathrm{~B}$ in $1.0 \mathrm{~min}$, then to $75 \% \mathrm{~B}$ in $3 \mathrm{~min}$, and then to $100 \% \mathrm{~B}$ in $2 \mathrm{~min}$. It was held at $100 \%$ B for 2.0 min before being returned to initial condition. The column was re-equilibrated for $2.0 \mathrm{~min}$. 
Table 3

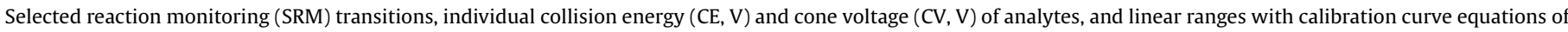
dansylated compounds.

\begin{tabular}{|c|c|c|c|c|c|c|c|c|c|c|c|}
\hline \multirow[t]{2}{*}{ Analyte } & \multirow[t]{2}{*}{ MW } & \multirow[t]{2}{*}[\mathrm{M}-\mathrm{H}]{$^{-}$} & \multicolumn{2}{|c|}{ Native } & \multicolumn{2}{|c|}{$\mathrm{PFBBr}$} & \multirow[t]{2}{*}[\mathrm{M}+233.8]{$^{+}$} & \multicolumn{4}{|c|}{ Dansyl chloride } \\
\hline & & & CE & $\mathrm{CV}$ & $\mathrm{CE}$ & $\mathrm{CV}$ & & CE & $\mathrm{CV}$ & $\begin{array}{l}\text { Linear range } \\
(\mathrm{ng} / \mu \mathrm{L})\end{array}$ & Equation \\
\hline E1 & 270.4 & $269.1>145.0$ & & & & & $504.1>171.1$ & 34 & & $0.0001-1$ & $\begin{array}{l}Y=3.899 X+0.010 \\
R^{2}=0.999\end{array}$ \\
\hline $\mathrm{E} 1-\mathrm{d}_{4}$ & 274.4 & $\begin{aligned}>143.0 \\
273.4>146.8\end{aligned}$ & 36 & 50 & 40 & 55 & $\begin{array}{r}>156.0 \\
508.1>171.0\end{array}$ & $\begin{array}{l}54 \\
34\end{array}$ & 50 & & \\
\hline E2 & 272.4 & $271.2>183.0$ & & & & & $506.1>171.1$ & 46 & & $0.001-1$ & $\begin{array}{l}Y=2.845 X+0.028 \\
R^{2}=0.998\end{array}$ \\
\hline $\mathrm{E} 2-\mathrm{d}_{4}$ & 276.1 & $\begin{array}{r}>144.8 \\
274.6>147.0\end{array}$ & 40 & 65 & 38 & 60 & $\begin{array}{r}>156.2 \\
510.1>171.0\end{array}$ & $\begin{array}{l}58 \\
46\end{array}$ & 55 & & \\
\hline E3 & 288.4 & $287.2>170.9$ & & & & & $522.2>171.1$ & 34 & & $0.0001-1$ & $\begin{array}{l}Y=3.542 X+0.019 \\
R^{2}=0.997\end{array}$ \\
\hline E3-d 3 & 291.4 & $\begin{array}{r}>145.0 \\
290.6>173.0\end{array}$ & 38 & 50 & 36 & 50 & $\begin{aligned} & >156.1 \\
525.2 & >171.0\end{aligned}$ & $\begin{array}{l}62 \\
34\end{array}$ & 60 & & \\
\hline EE2 & 296.4 & $295.2>144.8$ & & & & & $530.2>171.1$ & 34 & & $0.0001-1$ & $\begin{array}{l}Y=3.030 X-0.003 \\
R^{2}=0.998\end{array}$ \\
\hline EE2-d 4 & 300.4 & $\begin{array}{r}>159.0 \\
298.9>147.0\end{array}$ & 38 & 55 & 40 & 55 & $\begin{array}{r}>156.0 \\
534.2>171.0\end{array}$ & $\begin{array}{l}58 \\
34\end{array}$ & 60 & & \\
\hline NP & 220.4 & $219.2>133.0$ & 30 & 35 & 30 & 35 & $454.2>171.2$ & 32 & 45 & $0.05-3$ & $\begin{array}{l}Y=6.909 X+0.573 \\
R^{2}=0.999\end{array}$ \\
\hline & & $>147.0$ & & & & & $>156.1$ & 44 & & & \\
\hline $\mathrm{OP}$ & 206.3 & $205.0>133.2$ & & & & & $440.2>171.1$ & 34 & & $0.1-2$ & $\begin{array}{l}Y=11.17 X+4.823 \\
R^{2}=0.995\end{array}$ \\
\hline 4-n-Octyl-d17-phenol & 223.4 & $\begin{aligned} & >147.0 \\
222.1 & >107.6\end{aligned}$ & 25 & 35 & 24 & 45 & $\begin{aligned}>156.1 \\
457.2>171.0\end{aligned}$ & $\begin{array}{l}54 \\
34\end{array}$ & 50 & & \\
\hline BPA & 228.3 & $227.2>212.1$ & & & & & $462.1>171.2$ & 38 & & $0.05-3$ & $\begin{array}{l}Y=3.050 X+0.684 \\
R^{2}=0.997\end{array}$ \\
\hline BPA- ${ }^{13} \mathrm{C}_{12}$ & 240.2 & $\begin{aligned} & >132.8 \\
238.9 & >223.5\end{aligned}$ & 18 & 35 & 18 & 35 & $\begin{aligned} & >156.0 \\
474.1 & >171.0\end{aligned}$ & $\begin{array}{l}50 \\
38\end{array}$ & 45 & & \\
\hline BPA-d16 (RS) & 244.4 & $241.0>222.6$ & 22 & 35 & & & $478.0>171.0$ & 38 & 45 & & \\
\hline
\end{tabular}

Note: 4-n-Octyl-d17-phenol was used as internal standard of NP and OP.

2.5.3.2. APPI (-). Water (A) and methanol (B) were used as mobile phase. There were three LC conditions. (1) A BEH $C_{18}$ column had a gradient of $30 \%$ B for $1.0 \mathrm{~min}$, followed by a linear gradient to $50 \%$ $\mathrm{B}$ in $2.0 \mathrm{~min}$, then $75 \% \mathrm{~B}$ in $4.0 \mathrm{~min}$, and then $100 \% \mathrm{~B}$ in $2.0 \mathrm{~min}$. It was held at $100 \%$ B for 2.0 min before being returned to initial condition. The column was re-equilibrated for $4.0 \mathrm{~min}$. (2) An ODP 2 HP-2D column had a gradient of $50 \%$ B for $1.0 \mathrm{~min}$, followed by a linear gradient to $75 \% \mathrm{~B}$ in $1.5 \mathrm{~min}$, and then to $90 \% \mathrm{~B}$ in $5.0 \mathrm{~min}$, where it was held at $90 \%$ B for 1 min before being returned to initial condition. The column was re-equilibrated for $4.0 \mathrm{~min}$. (3) A RAM coupled with a Thermo Hypersil Gold column had a gradient of $30 \%$ B for $3.0 \mathrm{~min}$, followed by a linear gradient to $50 \%$ B in $1.0 \mathrm{~min}$, then to $75 \% \mathrm{~B}$ in $3.0 \mathrm{~min}$, and then to $100 \% \mathrm{~B}$ in $2.0 \mathrm{~min}$, at which point it was held at $100 \%$ B for $2.0 \mathrm{~min}$ before being returned to initial condition. The column was re-equilibrated for $2.0 \mathrm{~min}$.

2.5.3.3. APCI (-) and APCI/APPI (-). Water (A) and methanol (B) were used as mobile phase. There were three LC conditions. (1) A GP- $_{18}$ column had an initial gradient of $30 \%$ B, followed by a linear gradient to $50 \% \mathrm{~B}$ for $0.5 \mathrm{~min}$, then to $75 \% \mathrm{~B}$ in $2.0 \mathrm{~min}$, and then to $100 \%$ B in $0.5 \mathrm{~min}$. It was held at $100 \%$ B for $0.6 \mathrm{~min}$ before being returned to initial conditions. The column was re-equilibrated for $2.0 \mathrm{~min}$. (2) An ODP $2 \mathrm{HP}-4 \mathrm{D}$ column had a gradient of $50 \%$ B for $2.0 \mathrm{~min}$, followed by a linear gradient to $75 \% \mathrm{~B}$ in $1.5 \mathrm{~min}$, and then to $90 \%$ B in $3.5 \mathrm{~min}$, at which point it was held at $100 \%$ $B$ for 1.0 min before being returned to initial condition. The column was re-equilibrated for $4.0 \mathrm{~min}$. (3) A RAM coupled with a BetaBasic $\mathrm{C}_{18}$ column had a gradient of $30 \% \mathrm{~B}$ for $3.0 \mathrm{~min}$, followed by a linear gradient to $75 \% \mathrm{~B}$ in $1.0 \mathrm{~min}$, and then to $100 \%$
B in 4.0 min, where it was held at $100 \%$ B for 4.0 min before being returned to initial condition. The column was re-equilibrated for $3.0 \mathrm{~min}$.

\subsection{Method comparisons}

Because estrogenic compounds are frequently observed in sewage or surface water, it is difficult to obtain a matrix without estrogenic compounds. Raw water from a drinking water treatment plant (WTP) in Taipei City, which only contains analytes at trace levels, was used as the matrix. Equal aliquots from extracts of one-liter samples were used for each method. Eluates were concentrated to dryness at $45^{\circ} \mathrm{C}$ using a SpeedVac concentrator and were reconstituted by appropriate solvents, with or without the spiking of 90-ng native compounds for the following analyses: (1) native chemicals in ESI (-), APPI (-), APCI $(-)$ and APCI/APPI (-); (2) dansyl derivatization in ESI (+), APPI $(+)$, APCI $(+)$ and APCI/APPI (+); (3) PFBBr derivatization in EC-APNI (-). The best method was chosen for method validation based on signal intensities and matrix effects. The percentage matrix effect (\%ME) was used to assess matrix effects: peak area of post-extraction spiking/peak area of standard $\times 100$. Before calculation, the areas of samples without spiking were subtracted from the areas of samples.

\subsection{Method validation}

Two types of water, effluents and river water, were used for method validation. The effluents were sampled from a sewage treatment plant in Taipei. That plant is a secondary treatment facility with an activated sludge units. The samples were collected in 

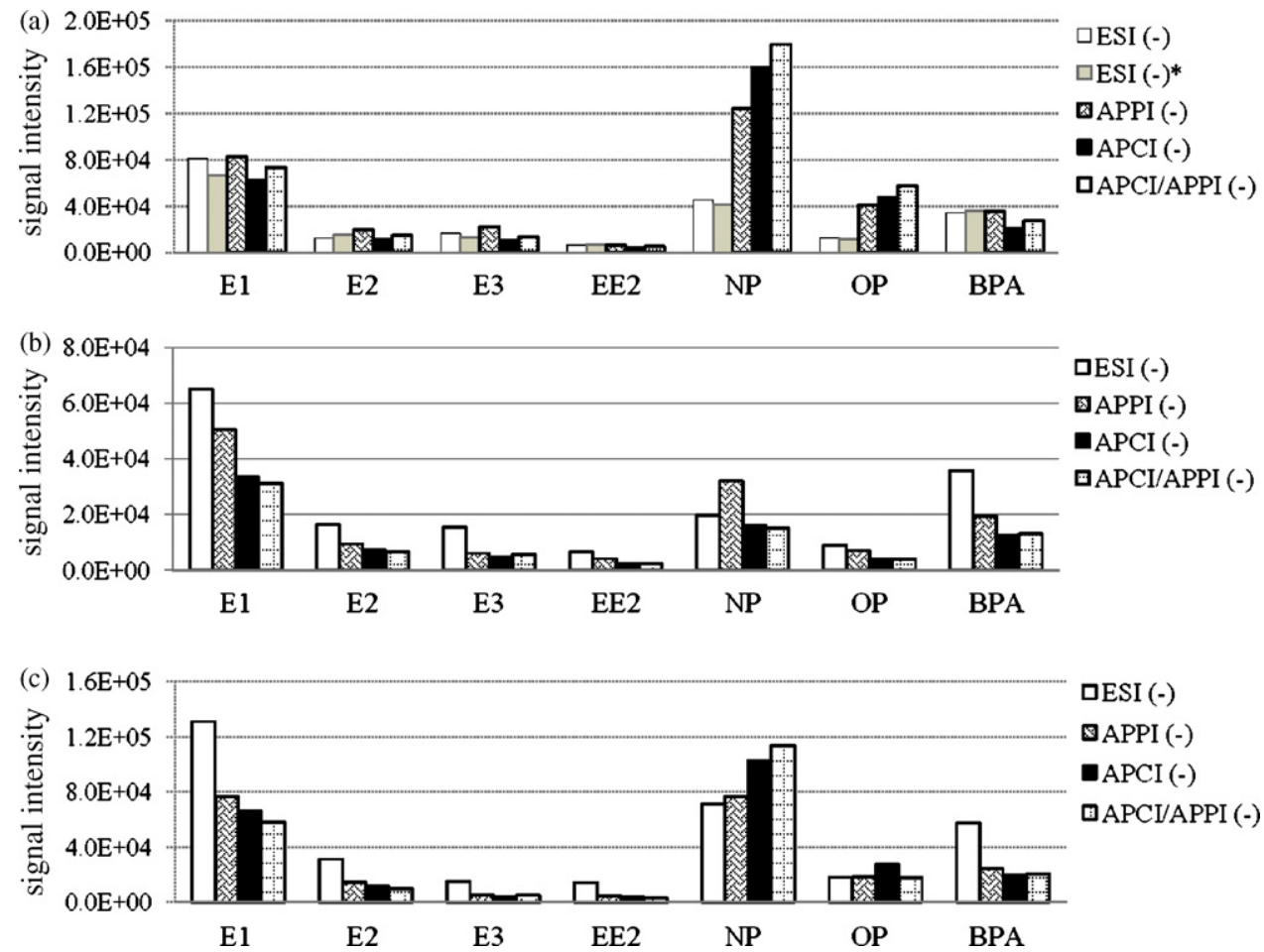

Fig. 2. Signal intensities of native analytes for various ion sources using (a) UPLC ( ${ }^{*}$ coupled with post-column split), (b) the mixed-mode column and (c) 2D-LC.

January $2008\left(\mathrm{pH} \mathrm{7.06}\right.$, temperature $\left.=21.0^{\circ} \mathrm{C}, \mathrm{DO}=4.29 \mathrm{mg} / \mathrm{L}\right)$. The river water was taken from the Kee-Lung River in Taipei in April $2008\left(\mathrm{pH} 7.0\right.$, temperature $\left.=22.4^{\circ} \mathrm{C}, \mathrm{DO}=1.2 \mathrm{mg} / \mathrm{L}\right)$. Three solutions, $0.25 \mathrm{ng} / \mu \mathrm{L}$ of the four estrogens standards $(20,100$, or $200 \mu \mathrm{L})$, $1 \mathrm{ng} / \mu \mathrm{L}$ of the three xenoestogens standards $(50,250$, or $500 \mu \mathrm{L})$ and $100 \mu \mathrm{L}$ of $0.5 \mathrm{ng} / \mu \mathrm{L}$ internal standards, were spiked into $0.5-\mathrm{L}$ water samples before extraction. Eluates from the SPE disk were concentrated to dryness at $45^{\circ} \mathrm{C}$ using the SpeedVac concentrator and were re-dissolved with $200-\mu \mathrm{L}$ anhydrous acetone containing $0.25 \mathrm{ng} / \mu \mathrm{L}$ recovery standard, and then reacted with dansyl chlo- ride derivatization reagent. Four-microliter solution was injected into LC/MS/MS.

\section{8. $Q A / Q C$, quantification and data analysis}

All glassware was rinsed with acetone, n-heptane, dichloromethane and methanol before being used for experiments. A blank sample spiked with the internal standards was run with each batch of samples to check experimental contamination and provide background levels of the native analytes. A
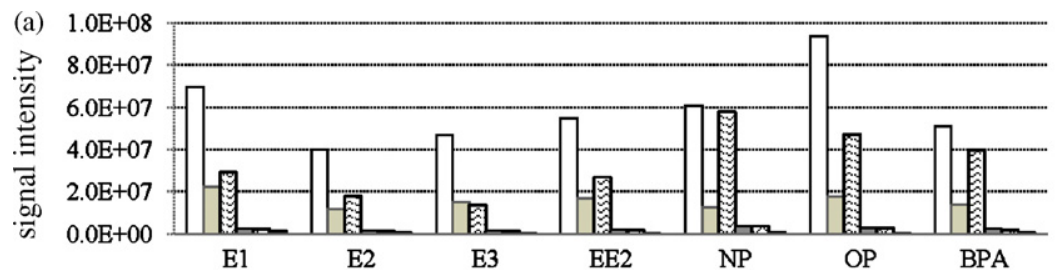

QESI $(+)$ 口ESI $(+)^{*}$

口APPI (+)

$\square \mathrm{APCI}(+)$

$\triangle \mathrm{APCI} / \mathrm{APPI}(+)$

$0.0 \mathrm{E}+00$

E1

E3

$\mathrm{OP}$

BPA
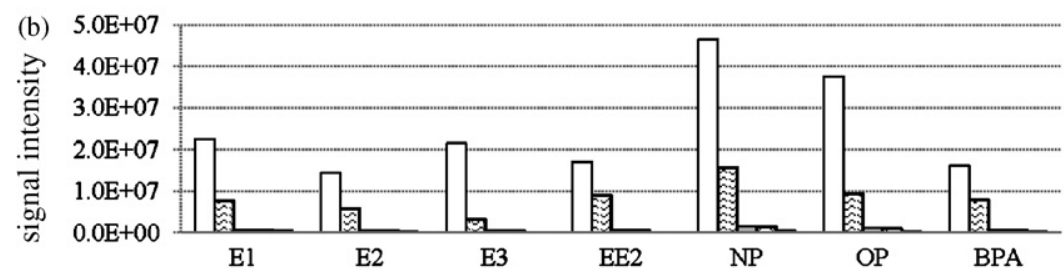

口ESI (+)

EAPPI $(+)$

$\square \mathrm{APCI}(+)$

$\square \mathrm{APCI} / \mathrm{APPI}(+)$

-ECAPNI (-)
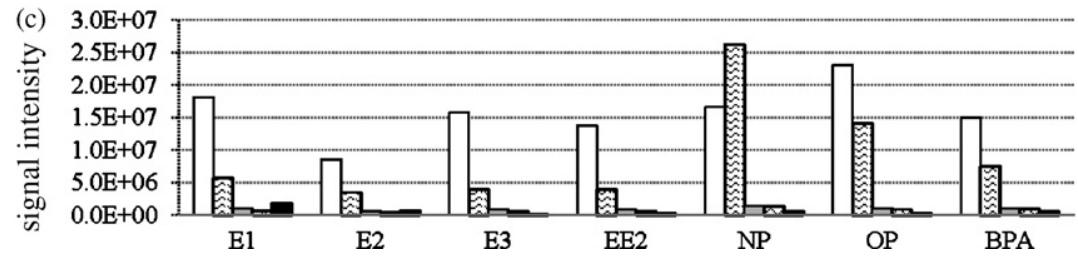

DESI (+)

口APPI $(+)$

口APCI $(+)$

DAPCI/APPI (+)

-ECAPNI (-)

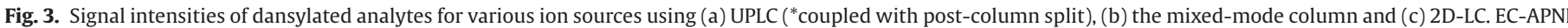
$(-)$ was for PFBBr derivatives. 

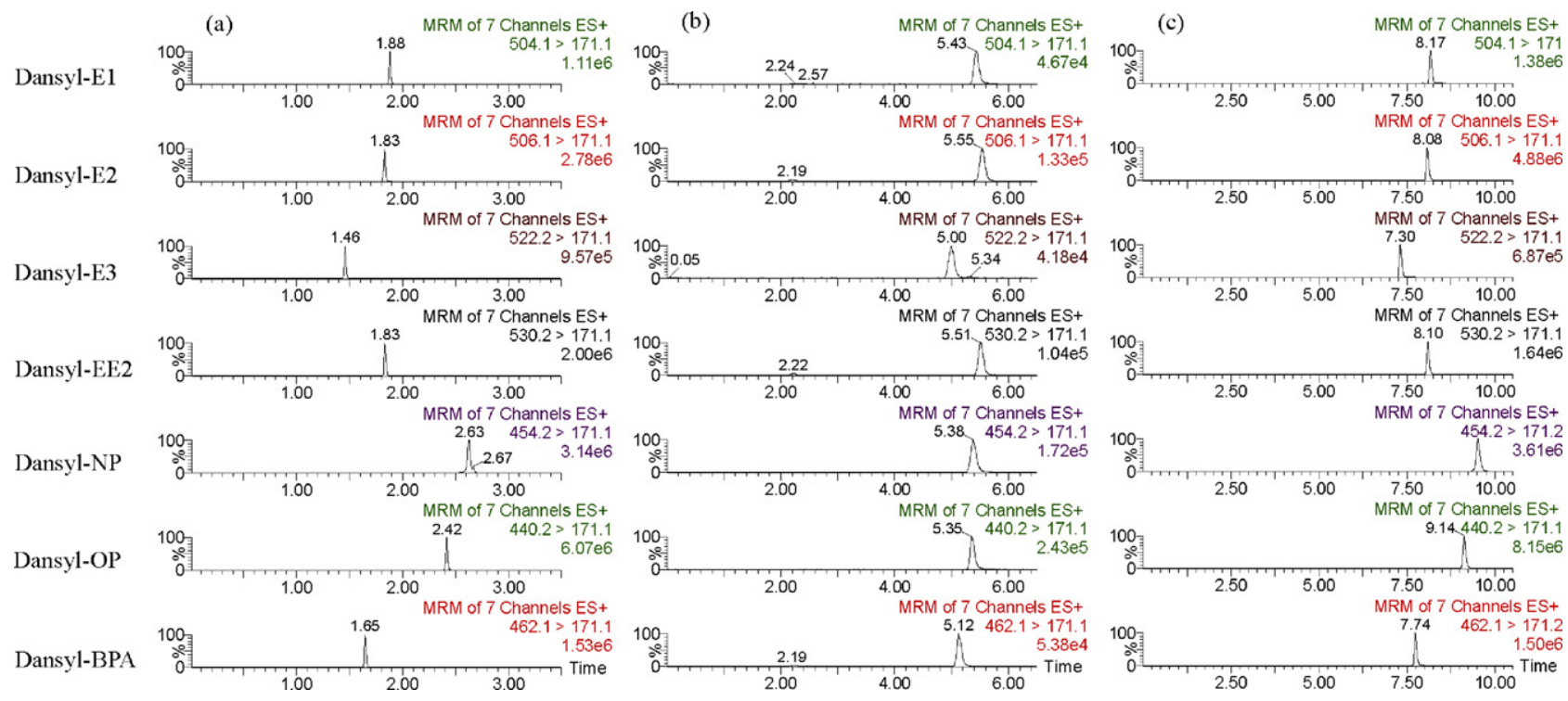

Fig. 4. Chromatograms of dansylated compounds ( $0.2 \mathrm{ng} / \mu \mathrm{L}$ of standards, $4-\mu \mathrm{L}$ injection) in ESI mode using (a) UPLC, (b) the mixed-mode column and (c) $2 \mathrm{D}-\mathrm{LC}$.

calibration curve was built at each analysis. The linear range were $0.0001-1 \mathrm{ng} / \mu \mathrm{L}$ for steroid estrogens (except E2 $0.001-1 \mathrm{ng} / \mu \mathrm{L}$ ) and $0.05-3 \mathrm{ng} / \mu \mathrm{L}$ for xenoestrogens (except OP $0.1-2 \mathrm{ng} / \mu \mathrm{L}$ ) at weighted $(1 / x)$. Isotope-dilution techniques were used to correct variations in sample preparation and instrumental performance; peak areas of dansylated analytes were normalized to their deuterium-labeled internal standard for quantification. The squares of correlation coefficients $\left(r^{2}\right)$ were 0.995 or above for all calibration curves as shown in Table 3. A one-way analysis of variance (ANOVA) with Tukey's post hoc comparison was used to compare the signal intensities and matrix effects associated with the different methods. Student's $t$-test was used to evaluate the difference of quantitative results between SRM and selected ion monitoring (SIM) method. SAS 9.1 was used to perform statistical analysis.

\section{Results and discussion}

3.1. Effects of dopant, mobile phase flow rates and compositions on APPI sensitivity

We found that excess dopant flow may or may not improve analyte signals, and optimal dopant portions were compounddependent. Different amount of the toluene dopant were tested on a
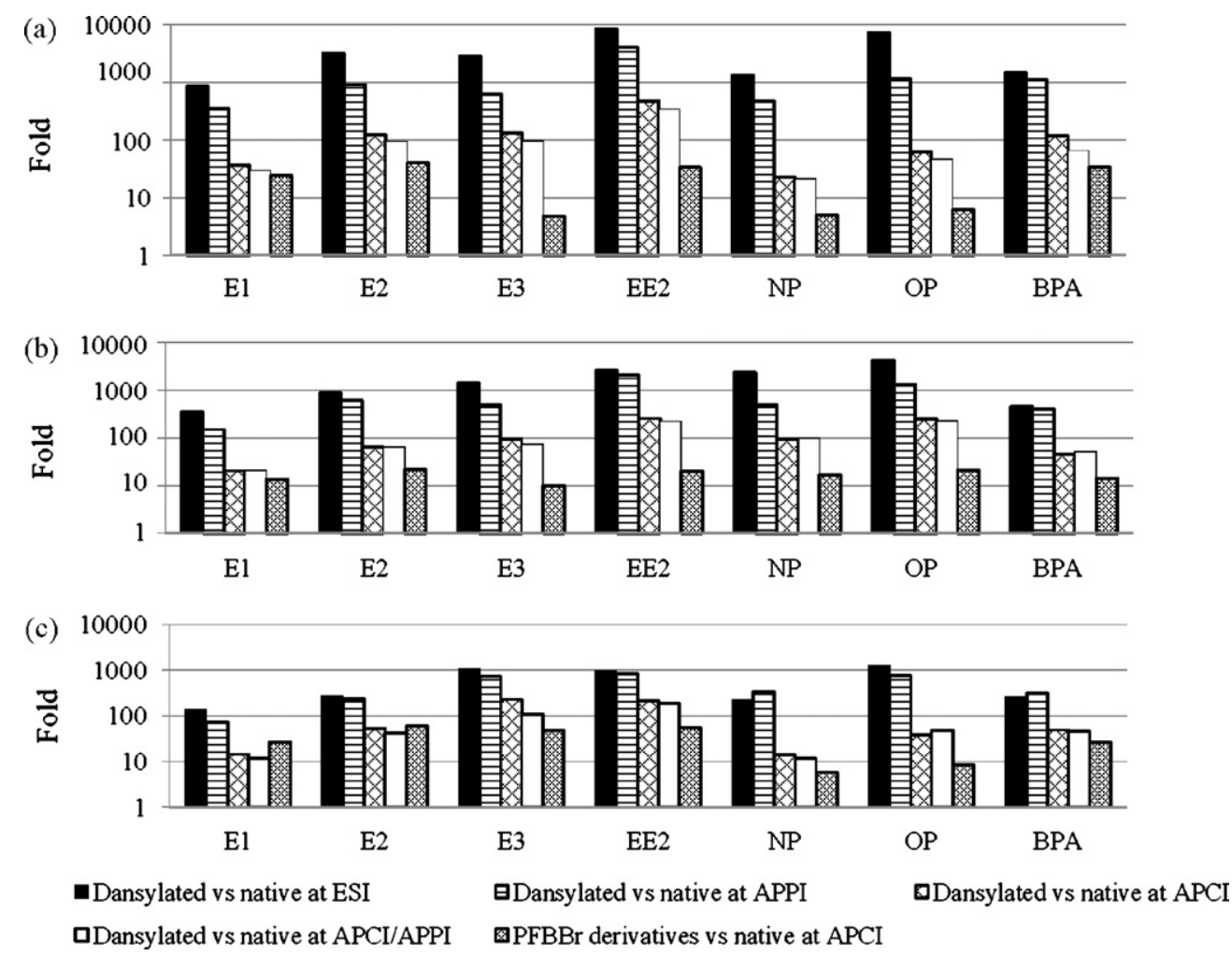

Fig. 5. Relative responses (in logarithmic scale) of derivatives to native analytes in different LC systems: (a) UPLC, (b) the mixed-mode column and (c) $2 D$-LC. 
Table 4

Matrix effect factor (\%) obtained from raw water samples using post-extraction spiking $(n=4)$.

\begin{tabular}{|c|c|c|c|c|c|c|c|}
\hline & E1 & E2 & E3 & EE2 & NP & OP & BPA \\
\hline \multicolumn{8}{|l|}{ Native at ESI (-) } \\
\hline $\operatorname{UPLC}(f=0.5 \mathrm{~mL} / \mathrm{min})$ & 88.1 & 66.6 & 86.0 & 75.1 & 92.5 & 87.6 & 78.0 \\
\hline UPLC with split $(f=0.1 \mathrm{~mL} / \mathrm{min})$ & 72.3 & 73.7 & 61.1 & 69.1 & 84.4 & 82.7 & 82.2 \\
\hline Mixed-mode column $(f=0.2 \mathrm{~mL} / \mathrm{min})$ & 75.9 & 76.5 & 74.1 & 73.5 & 77.3 & 78.2 & 76.2 \\
\hline $2 \mathrm{D}-\mathrm{LC}(f=0.2 \mathrm{~mL} / \mathrm{min})$ & 72.0 & 71.3 & 83.4 & 73.3 & 113 & 86.3 & 68.4 \\
\hline \multicolumn{8}{|l|}{ Native at APPI (-) } \\
\hline $\operatorname{UPLC}(f=0.2 \mathrm{~mL} / \mathrm{min})$ & $56.6^{\mathrm{a}}$ & $60.3^{\mathrm{a}}$ & $48.5^{\mathrm{a}}$ & $59.1^{\mathrm{a}}$ & $59.4^{\mathrm{a}}$ & $70.8^{c}$ & 53.4 \\
\hline Mixed-mode column $(f=0.2 \mathrm{~mL} / \mathrm{min})$ & $51.7^{\mathrm{a}}$ & $46.7^{\mathrm{a}}$ & $35.9^{\mathrm{a}}$ & $56.5^{\mathrm{a}}$ & $59.3^{\mathrm{a}}$ & $44.3^{\mathrm{a}, \mathrm{b}}$ & 55.5 \\
\hline $2 \mathrm{D}-\mathrm{LC}(f=0.2 \mathrm{~mL} / \mathrm{min})$ & $85.4^{\mathrm{b}, \mathrm{c}}$ & $81.7^{\mathrm{b}, \mathrm{c}}$ & $112^{\mathrm{b}, \mathrm{c}}$ & $95.5^{\mathrm{b}, \mathrm{c}}$ & $122^{\mathrm{b}, \mathrm{c}}$ & $88.3^{\mathrm{b}}$ & 50.5 \\
\hline \multicolumn{8}{|l|}{ Native at APCI (-) } \\
\hline $\operatorname{UPLC}(f=1.0 \mathrm{~mL} / \mathrm{min})$ & $52.0^{\mathrm{a}, \mathrm{c}}$ & $57.4^{\mathrm{a}, \mathrm{c}}$ & $95.9^{\mathrm{a}}$ & $58.7^{\mathrm{a}, \mathrm{c}}$ & $53.7^{c}$ & $56.2^{c}$ & 71.3 \\
\hline Mixed-mode column $(f=1.0 \mathrm{~mL} / \mathrm{min})$ & $84.2^{\mathrm{b}}$ & $86.7^{\mathrm{a}, \mathrm{b}}$ & 82.3 & $82.6^{\mathrm{b}}$ & $96.1^{\mathrm{b}}$ & $84.4^{\mathrm{a}, \mathrm{b}}$ & $82.9^{a}$ \\
\hline $2 \mathrm{D}-\mathrm{LC}(f=1.0 \mathrm{~mL} / \mathrm{min})$ & $76.4^{\mathrm{b}}$ & $72.3^{\mathrm{b}, \mathrm{c}}$ & $69.8^{\mathrm{b}}$ & $75.5^{\mathrm{b}}$ & 85.5 & $72.0^{\mathrm{b}}$ & $69.7^{\mathrm{b}}$ \\
\hline \multicolumn{8}{|l|}{ Native at APCI/APPI (-) } \\
\hline $\operatorname{UPLC}(f=1.0 \mathrm{~mL} / \mathrm{min})$ & $51.5^{c}$ & $62.5^{c}$ & 82.6 & $58.0^{c}$ & 51.8 & $53.9^{c}$ & $68.5^{\mathrm{c}}$ \\
\hline Mixed-mode column $(f=1.0 \mathrm{~mL} / \mathrm{min})$ & $88.8^{a, b}$ & $89.1^{a, b}$ & 93.0 & $91.6^{\mathrm{a}, \mathrm{b}}$ & 88.3 & $83.3^{\mathrm{s}, \mathrm{b}}$ & $95.5^{\mathrm{s}, \mathrm{b}}$ \\
\hline $2 \mathrm{D}-\mathrm{LC}(f=1.0 \mathrm{~mL} / \mathrm{min})$ & $54.6^{c}$ & $56.6^{c}$ & 92.2 & $55.5^{c}$ & 70.9 & $60.9^{c}$ & $62.5^{c}$ \\
\hline \multicolumn{8}{|l|}{ Dansyl at ESI (+) } \\
\hline $\operatorname{UPLC}(f=0.5 \mathrm{~mL} / \mathrm{min})$ & 94.6 & 96.0 & 92.2 & 92.0 & 63.5 & 59.6 & 78.6 \\
\hline UPLC with split $(f=0.1 \mathrm{~mL} / \mathrm{min})$ & 75.4 & 71.6 & 62.9 & 74.9 & 77.5 & 63.3 & 69.3 \\
\hline Mixed-mode column $(f=0.2 \mathrm{~mL} / \mathrm{min})$ & 82.3 & 79.8 & 77.3 & 81.8 & 60.8 & 58.9 & 79.4 \\
\hline $2 \mathrm{D}-\mathrm{LC}(f=0.2 \mathrm{~mL} / \mathrm{min})$ & 93.6 & 93.8 & 91.0 & 83.7 & 63.1 & 64.5 & 89.6 \\
\hline \multicolumn{8}{|l|}{ Dansyl at APPI (+) } \\
\hline $\operatorname{UPLC}(f=0.5 \mathrm{~mL} / \mathrm{min})$ & 85.7 & 85.8 & $104^{a, c}$ & 86.0 & $111^{\mathrm{c}}$ & $109^{a, c}$ & 67.8 \\
\hline Mixed-mode column $(f=0.5 \mathrm{~mL} / \mathrm{min})$ & 75.2 & 69.7 & $63.6^{\mathrm{b}}$ & 75.7 & $64.2^{\mathrm{a}, \mathrm{b}}$ & $72.2^{\mathrm{b}}$ & 52.8 \\
\hline $2 \mathrm{D}-\mathrm{LC}(f=0.5 \mathrm{~mL} / \mathrm{min})$ & 82.1 & 77.6 & $54.8^{\mathrm{b}}$ & 79.4 & $116^{c}$ & $78.5^{\mathrm{b}}$ & 42.9 \\
\hline \multicolumn{8}{|l|}{ Dansyl at APCI (+) } \\
\hline $\operatorname{UPLC}(f=1.0 \mathrm{~mL} / \mathrm{min})$ & 119 & 121 & 119 & 122 & 121 & 103 & 109 \\
\hline Mixed-mode column $(f=1.0 \mathrm{~mL} / \mathrm{min})$ & 111 & 112 & 120 & 113 & 131 & 101 & 81.3 \\
\hline $2 \mathrm{D}-\mathrm{LC}(f=1.0 \mathrm{~mL} / \mathrm{min})$ & 121 & 125 & 132 & 122 & 115 & 99.9 & 88.6 \\
\hline \multicolumn{8}{|l|}{ Dansyl at APCI/APPI (+) } \\
\hline $\operatorname{UPLC}(f=1.0 \mathrm{~mL} / \mathrm{min})$ & 109 & 109 & 107 & 115 & 103 & 88.9 & 61.9 \\
\hline Mixed-mode column $(f=1.0 \mathrm{~mL} / \mathrm{min})$ & 101 & 97.7 & 109 & 100 & 106 & 86.3 & 65.4 \\
\hline $2 \mathrm{D}-\mathrm{LC}(f=1.0 \mathrm{~mL} / \mathrm{min})$ & 107 & 108 & 120 & 108 & 90.4 & 122 & 71.6 \\
\hline \multicolumn{8}{|l|}{$\mathrm{PFBBr}$ at $\mathrm{APCI}(-)$} \\
\hline $\operatorname{UPLC}(f=1.0 \mathrm{~mL} / \mathrm{min})$ & 112 & 114 & 111 & 110 & 102 & 124 & 135 \\
\hline Mixed-mode column $(f=1.0 \mathrm{~mL} / \mathrm{min})$ & 110 & 110 & 99.6 & 113 & 106 & 97.9 & 108 \\
\hline $2 \mathrm{D}-\mathrm{LC}(f=1.0 \mathrm{~mL} / \mathrm{min})$ & 97.5 & 103 & 97.2 & 105 & 121 & 116 & 104 \\
\hline
\end{tabular}

Note: 3.6 ng equivalent of each analytes was injected.

a Statistically different from $2 \mathrm{D}-\mathrm{LC}$.

b Statistically different from UPLC.

c Statistically different from the mixed-mode column.

d Statistically different from UPLC with split.

Waters $\mathrm{BEH} \mathrm{C}_{18}$ column, ranging from $5 \%$ to $25 \%$ of a constant mobile phase flow rate at $500 \mu \mathrm{L} / \mathrm{min}$. The mobile phase compositions for native and dansylated compounds were Milli-Q water/methol and $10 \mathrm{mM}$ formic acid/acetonitrile, respectively, which were the optimal combinations for their separation on the column. Based on peak areas, the optimal amount of dopant for native analytes was 5\% of the mobile phase flow, $25 \mu \mathrm{L} / \mathrm{min}$. The intensities of dansylated analytes were gradually enhanced as toluene was increased to $20 \%$ of the mobile phase flow (corresponding to $100 \mu \mathrm{L} / \mathrm{min}$ ). All intensities were enhanced except for dansyl-NP and dansyl-OP, whose signals dropped significantly once the dopant exceeded $5 \%$. Therefore, a five-percent dopant flow was used in this study. Robb et al. used acridine and 9-methylanthracene as model compounds and reported that the signals are close to plateaus when the dopant amount ranges from $5 \%$ to $10 \%$ of the mobile phase flows, which were at 50, 200, or $1000 \mu \mathrm{L} / \mathrm{min}$ [27] and signal intensities are slightly raised when a higher dopant percentage is given [27], a finding similar to ours in native and dansylated steroid estrogens and dansylated BPA; however, in our study, signals of dansylated NP and OP dropped when the dopant portion was higher than $5 \%$.
The suitable flow rate of mobile phase for APPI signals was compound-dependent, which the best flow rates were different between native and dansylated analytes. The mobile phase flow rates of $100,200,500$ and $1000 \mu \mathrm{L} / \mathrm{min}$ were evaluated at a constant dopant of $5 \%$ mobile phase flows using an isocratic liquid chromatography; the mobile phase compositions of native and dansylated analytes were $20 \%$ Milli-Q water $/ 80 \%$ methanol $(\mathrm{v} / \mathrm{v})$ and $12 \% 10$-mM formic acid/88\% acetonitrile $(\mathrm{v} / \mathrm{v})$, respectively. A Sepax GP-C $\mathrm{C}_{18}$ column $(3.0 \mathrm{~mm} \times 100 \mathrm{~mm}, 3 \mu \mathrm{m})$ was used at a flow rate of $1.0 \mathrm{~mL} / \mathrm{min}$ and a Waters BEH $\mathrm{C}_{18}$ column $(2.1 \mathrm{~mm} \times 100 \mathrm{~mm}$, $1.7 \mu \mathrm{m}$ ) was performed at equal or less than $500 \mu \mathrm{L} / \mathrm{min}$. The best sensitivities of native and dansylated analytes were obtained at flow rates of 200 and $500 \mu \mathrm{L} / \mathrm{min}$, respectively. The signal intensities of native analytes at a flow rate of $200 \mu \mathrm{L} / \mathrm{min}$ were 1.6 - to 2.8 -fold, 1.0- to 1.6-fold, and 2.7- to 6.4-fold higher than those at flows of 100,500 , and $1000 \mu \mathrm{L} / \mathrm{min}$, respectively. The signal intensities of dansylated analytes at a flow rate of $500 \mu \mathrm{L} / \mathrm{min}$ were 4.9 - to 18 fold, 3.1 - to 9.4-fold, and 2.2- to 6.0-fold higher than those at flows of 100,200 , and $1000 \mu \mathrm{L} / \mathrm{min}$, respectively.

Some studies have demonstrated that a low flow rate (e.g. $\leq 100 \mu \mathrm{L} / \mathrm{min}$ ) may improve the ionization efficiency of APPI 
resulting from lower photoabsorption by solvent [27-29]. However, our data showed that a lower flow rate may not provide a better efficiency in APPI. To confirm these observations, we further utilized a BEH $\mathrm{C}_{18}$ column with a smaller I.D. $(1.0 \mathrm{~mm} \times 100 \mathrm{~mm}$, $1.7 \mu \mathrm{m})$. Its optimal flow rate is $100 \mu \mathrm{L} / \mathrm{min}$. We found that the signal response was even weaker than that used a larger column I.D. $(2.1 \mathrm{~mm} \times 100 \mathrm{~mm}, 1.7 \mu \mathrm{m})$. Solvent molecules (e.g. methanol) may be involved in the ionization process, especially in the dopantassisted APPI, and the ions formed by proton transfer are less affected by high flow rates than those formed via charge exchange $[25,28,30,31]$. This would explain the reason that the optimal mobile phase flow rates on APPI efficiencies were compounddependent.

Mobile phase composition is also critical to APPI sensitivity, and is also compound-dependent. For native analytes, a Milli-Q water-methanol combination gave better responses with better peak shapes than those using water-acetonitrile; however, for dansylated analytes, a composition of $10 \mathrm{mM}$ formic acid-acetonitrile provided two to three times higher sensitivity than a composition of $10 \mathrm{mM}$ formic acid-methanol. Cai et al. indicated that methanol has a lower photoabsorption cross-section than acetonitrile, and its dimmers can be ionized by a Kr Lamp (acetonitrile cannot) [25]; consequently, use of methanol would theoretically provide a better response, which was correct for native analytes in this study but was not the case for dansylated analytes. However, Cal et al. also proposed that the APPI mechanism is much more complex, and other factors, such as the ionization potential of analytes and the relative proton affinity of solvents and analytes, may affect APPI efficiencies as well [25].

\subsection{Comparison of signal intensity between derivatized and underivatized analytes}

The best combinations of LC systems and ion sources for native and dansylated analytes were 2D-LC and UPLC coupled with ESI mode, respectively. Signals of all native analytes in ESI (-) mode were better than those in APPI $(-)$, APCI $(-)$ and APCI/APPI (-) except for NP and OP; there was no significant difference in signal intensities between APCI/APPI dual mode and APCI or APPI alone (Fig. 2). Within the ESI mode, 2D-LC was superior to UPLC and mixed-mode column in terms of signal intensities, but UPLC outperformed both 2D-LC and mixed-mode columns when APPI (-), APCI $(-)$ and APCI/APPI $(-)$ were put on. For PFBBr derivatives using ECAPNI (-), it was better to use 2D-LC than UPLC for the analysis of E1, E2, E3 and EE2, but it was better to use UPLC rather than 2D-LC for the analysis of NP, OP and BPA. With regard to the signal intensities of the dansylated analytes, ESI (+) were much better than other ion sources (except for NP); the APCI/APPI dual mode produced similar signal intensities with those of APCI alone, but was much inferior to those of APPI alone. In addition, use of UPLC produced much stronger responses of dansylated analytes relative to other two LC systems in all ion sources (Fig. 3). Based on the results, the on-line cleanup of the mixed-mode column and the RAM pre-column did not gave them a decisive advantage over UPLC on detecting the analytes in raw water samples, especially for dansylated derivatives. The mixed-mode column and 2D-LC, a polymer-based column and a coupled-column system, respectively, offered good peak shapes at widths $<0.3 \mathrm{~min}$ (Fig. 4); nevertheless, UPLC provided sharp peaks at a width of about $0.06 \mathrm{~min}$ (except for NP, which was 0.14 min due to a mixture of isomers).

Derivatization with dansyl chloride and PFBBr significantly improved the detection sensitivity relative to underivatized analytes, and the dansylated analytes produced much better responses in four ionization methods than $\mathrm{PFBBr}$ derivatives in EC-APNI (Fig. 3). The trends of signal enhancement of derivatization among various ionization methods were similar, which were

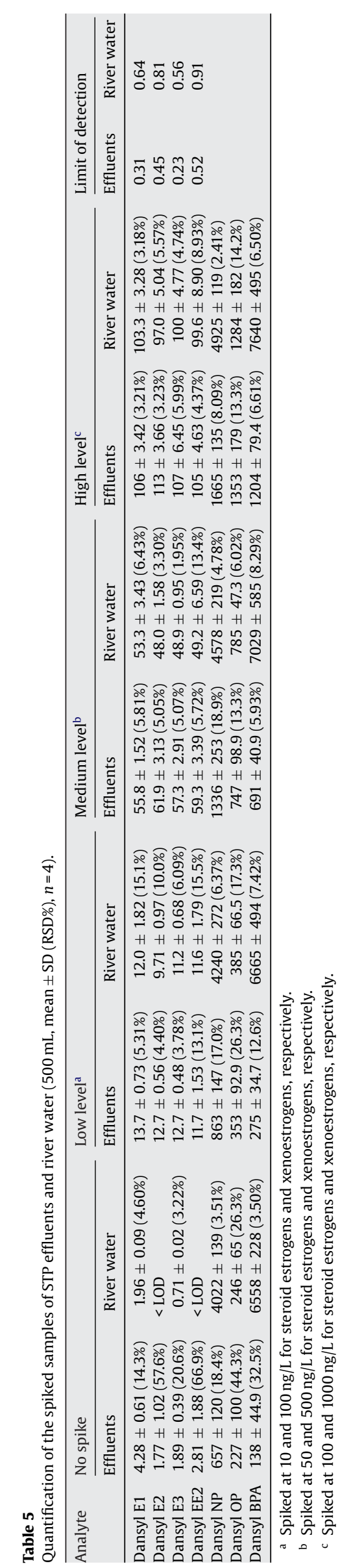


independent on the LC systems (Fig. 5). For example, on UPLC column, the signal enhancements were 859-8460 times, 354-4030 times, 23-472 times, 21-344 times and 5-41 times in ESI, APPI, APCI, APCI/APPI and EC-APNI, respectively, relative to the native analytes. In other words, the order of responses of derivatized analytes versus underivatized ones in ionization methods was $\mathrm{ESI}>\mathrm{APPI}>\mathrm{APCI} \fallingdotseq \mathrm{APCI} / \mathrm{APPI}>\mathrm{EC}-\mathrm{APNI}$. In addition, post-column split (a flow rate at $100 \mu \mathrm{L} / \mathrm{min}$ after split) in this study did not increase response in ESI mode (Fig. 3). In contrast, Kloepfer et al. reported that a lower flow rate (e.g. down to $20 \mu \mathrm{L} / \mathrm{min}$ ) can dramatically increase signal intensities of some analytes, although some other analytes were unaffected [32].

\subsection{Matrix effect}

It was inconclusive to determine which LC systems and ion sources were least susceptible to matrix effects (i.e., higher values of matrix effect factors) when using the raw water as the matrix (Table 4), which is a source for drinking water and may be cleaner than usual surface water; however, we did observe that derivatized analytes were less prone to matrix effects than underivatized ones. For native analytes, we found no significant differences in matrix effect factors among the different LC systems with ESI mode; however, the matrix effect was lower on 2D-LC for APPI, and it was lower on the mixed-mode column for APCI and APCI/APPI. There were no significant differences in matrix effect factors among $L C$ systems for dansylated analytes in all sources (except for APPI) and for PFBBr derivatives in EC-APNI.

Because the signal intensities of dansylated analytes using ESI and APPI were much more intense than others, we further investigated the matrix effects of these two sources on dansylated analytes using river water, which is a more complex matrix comparing with the raw water and may contain higher levels of analytes. The endogenous analytes in the river water may influence our determination on matrix effect factors; to avoid this potential problem, we spiked stable isotope-labeled analytes to the residues after extraction (the levels were equivalent to $80 \mathrm{ng} / \mathrm{L}$ in the water) before

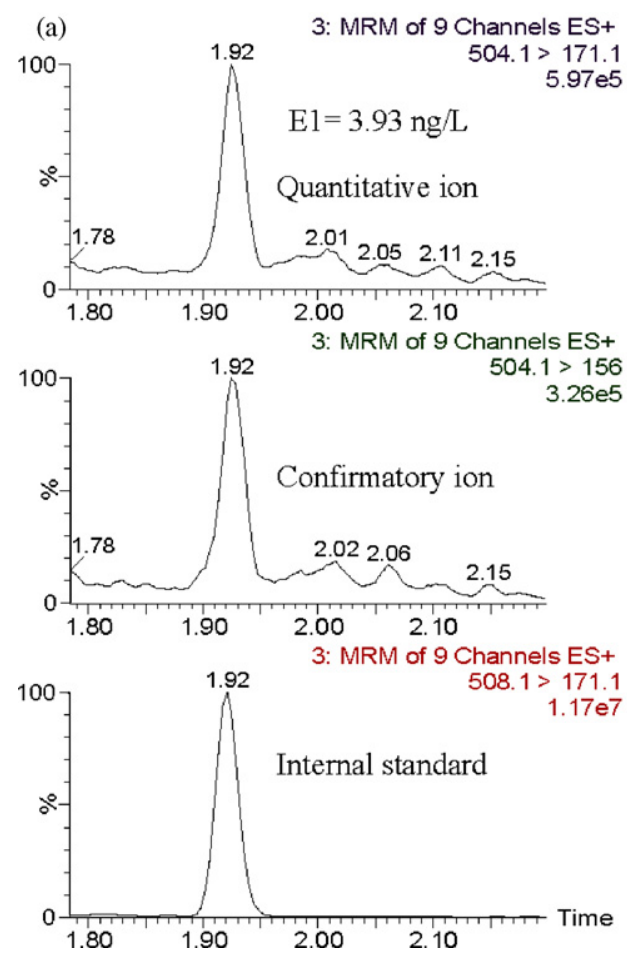

derivatization with dansyl chloride. The matrix effect factors of ESI using UPLC, UPLC with post-column split, mixed-mode column and 2D-LC were 17.7\%-70.3\%, 22.0\%-57.3\%, 40.2\%-60.4\% and $16.1 \%-62.1 \%$, respectively; the factor values of APPI using UPLC, mixed-mode column and 2D-LC were $15.7 \%-46.7 \%, 25.9 \%-49.9 \%$ and $22.1 \%-63.2 \%$, respectively. Therefore, the matrix effect of ESI and APPI were similar under the same LC conditions, and none of the four LC systems could significantly eliminate ion suppression. The cutoff of molecular mass for RAM pre-column is about $15 \mathrm{kDa}$; consequently, the RAM column could not eliminate the matrix effect caused by small molecules [32]. In a previous study, Kloepfer et al. reported that a post-column split (down to $20-100 \mu \mathrm{L} / \mathrm{min}$ ) not only enhances sensitivity but also reduces ion suppression by $40-60 \%$ in wastewater samples [32]; However, the UPLC with postcolumn split did not reduce matrix effects significantly comparing with that without split in our study.

\subsection{Method validation}

Because dansyl derivatization under UPLC coupled with ESI provided the best performance based on the sensitivity and matrix effect, we validated this method. Good accuracy and precision were obtained for calibration curves. The intra-day and inter-day accuracy were within $2 \%$ and $9 \%$, respectively; the inter-day variations (RSD\%) ranged from $0.88 \%$ to $14.6 \%$ and intra-day responses were almost identical. The linearity of calibration curves of steroid estrogens (1000-fold to 10,000 -fold) are similar or better than those of Qin et al. $(0.2-200 \mathrm{ng} / \mathrm{mL}, 1000$-fold) [20] and Vulliet et al. (0.05-20 ng/mL, 400-fold) [33].

No steroid estrogens were detected in any laboratory blank, but NP, OP and BPA were detected using dansyl derivatization; the background levels in the reagent blanks of Milli-Q water were $60-130 \mathrm{ng} / \mathrm{L}$. The possible sources of NP, OP and BPA could be the speedisk for solid phase extraction (packed in a plastic disk vessel), the Milli-Q water itself (plastic materials in the waterpurified system) or the derivatization process. For example, during the derivatization procedure, reagents $\left(\mathrm{NaHCO}_{3} / \mathrm{NaOH}\right.$ buffer and

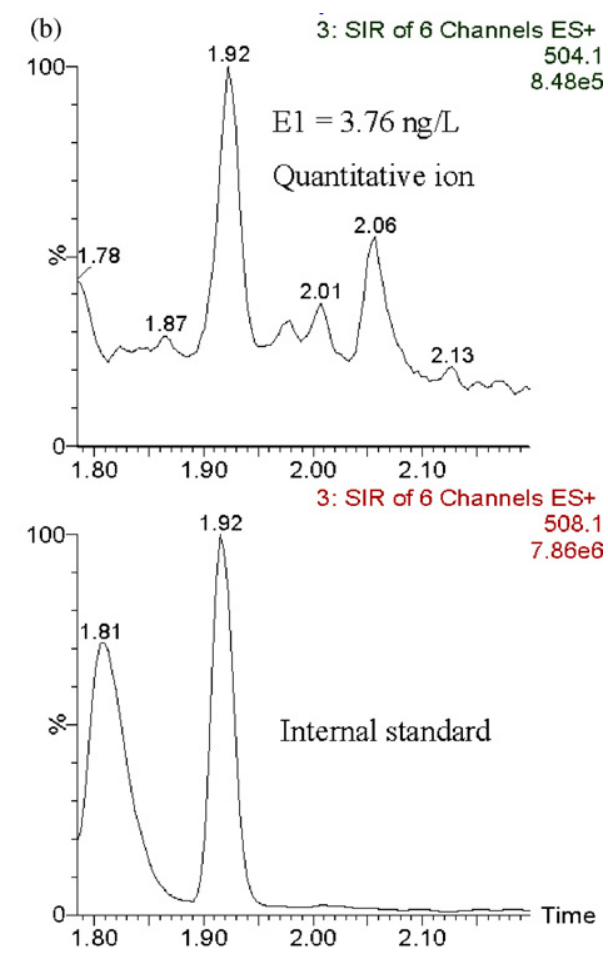

Fig. 6. Chromatograms of dansyl-E1 in effluents from a sewage treatment plant between: (a) SRM and (b) SIM mode. 
$\mathrm{KOH} /$ anhydrous $\mathrm{EtOH}$ ) were prepared in plastic containers, $\mathrm{pH}$ was adjusted using plastic droppers, and plastic tips were utilized to spike solutions and reagents. On the other hand, the blank levels were insignificant to those found in environment samples.

The method was used with samples from STP effluents and river water (Table 5). The mean concentrations of steroid estrogens in effluents were $4.3 \mathrm{ng} / \mathrm{L}$ for E1, $1.8 \mathrm{ng} / \mathrm{L}$ for E2, $1.9 \mathrm{ng} / \mathrm{L}$ for E3, and $2.8 \mathrm{ng} / \mathrm{L}$ for EE2; NP, OP and BPA were found in much higher concentrations with mean values of 657,227 , and $138 \mathrm{ng} / \mathrm{L}$, respectively. For steroid estrogens in river water, only E1 and E3 were detected at 2.0 , and $0.72 \mathrm{ng} / \mathrm{L}$, respectively; the concentrations of NP, OP and $\mathrm{BPA}$ in river water were higher than those in effluents with mean values of 4022,246 , and $6558 \mathrm{ng} / \mathrm{L}$, respectively. High levels of NP and BPA in river water in Taiwan have also been observed by Ding et al. [34,35].

Three different concentrations (10,50, $100 \mathrm{ng} / \mathrm{L}$ for steroid estrogens and 100, 500 and $1000 \mathrm{ng} / \mathrm{L}$ for xenoestrogens) were spiked into the water samples from the same sources to evaluate the method accuracy and precision (four duplicates each level). The reported concentrations of spiked samples did not deduct the background levels in the water. In our study, RSD\% of all spiked samples were all smaller than $15.5 \%$ except for NP and OP spiked at $100 \mathrm{ng} / \mathrm{L}$ (and $500 \mathrm{ng} / \mathrm{L}$ for NP), which were close to the endogenous levels of the samples (Table 5). We found that the measured concentrations were very close to the spiked levels if the backgrounds (no spike) were deducted (Table 5).

Because of the existing backgrounds of NP, OP, and BPA, it is impractical to calculate their limits of detection (LODs); therefore, we only reported the LODs $(\mathrm{S} / \mathrm{N}=3: 1)$ of E1, E2, E3 and EE2, which ranged between 0.23 and $0.52 \mathrm{ng} / \mathrm{L}$ for STP effluents and between 0.56 and $0.91 \mathrm{ng} / \mathrm{L}$ for river water (Table 5). Qin et al. also reported good method detection limits (MDL) of $0.038-0.13 \mathrm{ng} / \mathrm{L}$ for river water of $500 \mathrm{~mL}$ using dansyl chloride derivatization [20]. In addition, Vulliet et al. showed excellent LODs of $0.01-0.20 \mathrm{ng} / \mathrm{L}$ without chemical derivatization for 1 -L groundwater, which may result from good recoveries and a large-volume injection $(100 \mu \mathrm{L})$ [33]. Although tandem-MS methods (SRM) provide better sensitivity and selectivity than those of single-MS methods (SIM), most labs cannot afford tandem-MS instruments. However, this study, for example, was able to detect steroid estrogens in all real samples of STP effluents with SIM after dansyl derivatization, and the measured levels of either spiked or non-spiked samples were similar to those using SRM (Fig. 6). The LODs of steroid estrogens in effluents using SIM were $1.03-1.75 \mathrm{ng} / \mathrm{L}$. The on-column detection limits of dansylated steroid estrogens with SRM and SIM were 0.05-0.20 and $0.44-1.48 \mathrm{pg}$, respectively.

\section{Conclusions}

In this study, we present a quantitative method for the analysis of seven estrogenic compounds with dansyl derivatization in both SIM and SRM. With the improvement in sensitivity using UPLC and chemical derivatization method, environmental levels of these chemicals can be determined using a single MS instead of the more expensive tandem-MS. The instrumental throughput was significantly increased, with a run in 3.2 min plus 1 -min re-equilibrium time. We exhaustively investigated the performance of common ionization probes and different LC systems. ESI is usually reported to more subject to ion suppression than APCI and APPI, but this was not the case in this study. Although a mixed-mode column or the RAM pre-column did not substantially reduce the matrix effects better than UPLC for the water matrixes we tested, their use with other matrixes, such as food or tissues, are worth further explorations.

\section{Acknowledgement}

This work is supported by the National Science Council, Taiwan (NSC 96-2314-B-002-101-MY2).

\section{References}

[1] B.R. Carr, J.E. Griffin, in: J.D. Wilson, D.W. Foster, H.M. Kronenberg, L.P. Reed (Eds.), Williams Textbook of Endocrinology, W. B. Saunders Company, Philadelphia, 1998, p. 901.

[2] A.C. Johnson, A. Belfroid, A. Di Corcia, Sci. Total Environ. 256 (2000) 163.

[3] C. Baronti, R. Curini, G. D’Ascenzo, A. Di Corcia, A. Gentili, R. Samperi, Environ. Sci. Technol. 34 (2000) 5059.

[4] B. Stachel, U. Ehrhorn, O.P. Heemken, P. Lepom, H. Reincke, G. Sawal, N. Theobald, Environ. Pollut. 124 (2003) 497.

[5] U. Bolz, H. Hagenmaier, W. Korner, Environ. Pollut. 115 (2001) 291.

[6] H.M. Kuch, K. Ballschmiter, Environ. Sci. Technol. 35 (2001) 3201.

[7] S. Rodriguez-Mozaz, M.J. de Alda, D. Barcelo, J. Chromatogr. A 1045 (2004) 85.

[8] L. Salste, P. Leskinen, M. Virta, L. Kronberg, Sci. Total Environ. 378 (2007) 343.

[9] C.Y. Chen, T.Y. Wen, G.S. Wang, H.W. Cheng, Y.H. Lin, G.W. Lien, Sci. Total Environ. 378 (2007) 352.

[10] T. Benijts, R. Dams, W. Lambert, A. De Leenheer, J. Chromatogr. A 1029 (2004) 153.

[11] H. Kondo, Y. Okada, K. Shimbo, Y. Fusho, Eastern Analytical Symposium and Exhibit (EAS), Somerset, New Jersey, USA, 2006.

[12] J. Chico, S. Meca, R. Companyo, M.D. Prat, M. Granados, J. Chromatogr. A 1181 (2008) 1 .

[13] E.A. Hogendoorn, E. Dijkman, B. Baumann, C. Hidalgo, J.V. Sancho, F. Hernandez, Anal. Chem. 71 (1999) 1111.

[14] E.T. Gangl, M.M. Annan, N. Spooner, P. Vouros, Anal. Chem. 73 (2001) 5635

[15] C.L. Andrews, C.P. Yu, E. Yang, P. Vouros, J. Chromatogr. A 1053 (2004) 151.

[16] M.R. Anari, R. Bakhtiar, B. Zhu, S. Huskey, R.B. Franklin, D.C. Evans, Anal. Chem. 74 (2002) 4136.

[17] A. Salvador, C. Moretton, A. Piram, R. Faure, J. Chromatogr. A 1145 (2007) 102.

[18] G. Singh, A. Gutierrez, K. Xu, I.A. Blair, Anal. Chem. 72 (2000) 3007.

[19] W.Z. Shou, X.Y. Jiang, N.D. Weng, Biomed. Chromatogr. 18 (2004) 414.

[20] F. Qin, Y.Y. Zhao, M.B. Sawyer, X.F. Li, Anal. Chim. Acta 627 (2008) 91.

[21] R.E. Nelson, S.K. Grebe, D.J. O’Kane, R.J. Singh, Clin. Chem. 50 (2004) 373.

[22] L. Song, A.D. Wellman, H. Yao, J. Adcock, Rapid Commun. Mass Spectrom. 21 (2007) 1343.

[23] Y.H. Lin, C.Y. Chen, G.S. Wang, Rapid Commun. Mass Spectrom. 21 (2007) 1973.

[24] R. Mohamed, Y.A. Hammel, M.H. LeBreton, J.C. Tabet, L. Jullien, P.A. Guy, J. Chromatogr. A 1160 (2007) 194.

[25] S.S. Cai, L.C. Short, J.A. Syage, M. Potvin, J.M. Curtis, J. Chromatogr. A 1173 (2007) 88.

[26] L.P. Penzes, G.W. Oertel, J. Chromatogr. 51 (1970) 325.

[27] D.B. Robb, M.W. Blades, J. Am. Soc. Mass Spectrom. 16 (2005) 1275.

[28] T.J. Kauppila, A.P. Bruins, R. Kostiainen, J. Am. Soc. Mass Spectrom. 16 (2005) 1399.

[29] D.B. Robb, M.W. Blades, J. Am. Soc. Mass Spectrom. 17 (2006) 130.

[30] L.C. Short, K.A. Hanold, S.S. Cai, J.A. Syage, Rapid Commun. Mass Spectrom. 21 (2007) 1561.

[31] L.C. Short, S.S. Cai, J.A. Syage, J. Am. Soc. Mass Spectrom. 18 (2007) 589.

[32] A. Kloepfer, J.B. Quintana, T. Reemtsma, J. Chromatogr. A 1067 (2005) 153.

[33] E. Vulliet, L. Wiest, R. Baudot, M.F. Grenier-Loustalot, J. Chromatogr. A 1210 (2008) 84.

[34] C.Y. Cheng, C.Y. Wu, C.H. Wang, W.H. Ding, Chemosphere 65 (2006) 2275.

[35] W.H. Ding, C.Y. Wu, J. Chin. Chem. Soc-Taip. 47 (2000) 1155. 